\title{
Evaluation of a phase-based motion tracking method for the calculation of myocardial stress and strain from tagged MRI
}

\author{
Lennart Tautz $^{1 *}$, Anja Hennemuth ${ }^{1}$, Teodora Chitiboi ${ }^{1}$, Ulrich Kramer $^{2}$ \\ From 17th Annual SCMR Scientific Sessions \\ New Orleans, LA, USA. 16-19 January 2014
}

\section{Background}

Tagged MRI is an established technique for the tracking of local deformations of the myocardium. The quantitative assessment of myocardial stress and strain is however a non-trivial task and only few software tools are available for clinical use. The purpose of this work was the evaluation of a phase-based motion tracking method for fully automatic calculation of deformation parameters from tagged MRI sequences [1].

\section{Methods}

We calculated motion fields which form the basis for the computation of myocardial stress and strain for 40 singleslice tagged MR image sequences of healthy subjects. Image data was acquired at two different sites with four different MR scanners (Siemens Espree 1.5T, Avanto 1.5T, Trio 3T and Biograph 3T). Tagging grid spacing ranged from 6 to $8 \mathrm{~mm}$, and in-plane resolutions from 1.2 to 1.6 $\mathrm{mm}$. Images were oriented in short-axis (39) and 2chamber view (1). The phase-based motion tracking approach estimates local deformation based on the application of quadrature filters [2]. The resulting motion field can then be used for motion tracking as well as for the calculation of stress and strain. For the assessment of the motion field quality, tracked landmarks were compared with expert observations. Two observers placed corresponding landmarks on tagging line crossings in $5(2 \mathrm{CH})$ or 6 (SAX) AHA segments of the myocardium in all image sequences. Inter-observer difference as well as deviation from the automatically tracked landmarks was calculated.

\section{Results}

Calculation time of the automatic motion tracking algorithm was $39.13 \pm 36.98 \mathrm{~s}$ on average per data set. The average deviation of the tracked landmark positions from the observer annotations was $0.43 \pm 0.35 \mathrm{~mm}$, and the average inter-observer difference was $1.17 \pm 1.43$ $\mathrm{mm}$. The highest errors occurred for timeframes with rapidly moving myocardium and temporarily hidden tag lines due to throughplane motion.

\section{Conclusions}

Altogether, automatic tracking error was in the order of magnitude of the voxel resolution, and is lower than the inter-observer difference. The evaluation shows that the method is capable of quantifying motion from tagged MRI data as well as manual observers. We thus assume that the method is suited for the calculation of clinically relevant parameters, such as circumferential and radial strain. The presented method is integrated into an OsiriX plugin that has been made available for clinical research.

\section{Funding}

This work was partially funded by the European Regional Development Fund.

${ }^{1}$ Fraunhofer MEVIS, Bremen, Germany

Full list of author information is available at the end of the article 


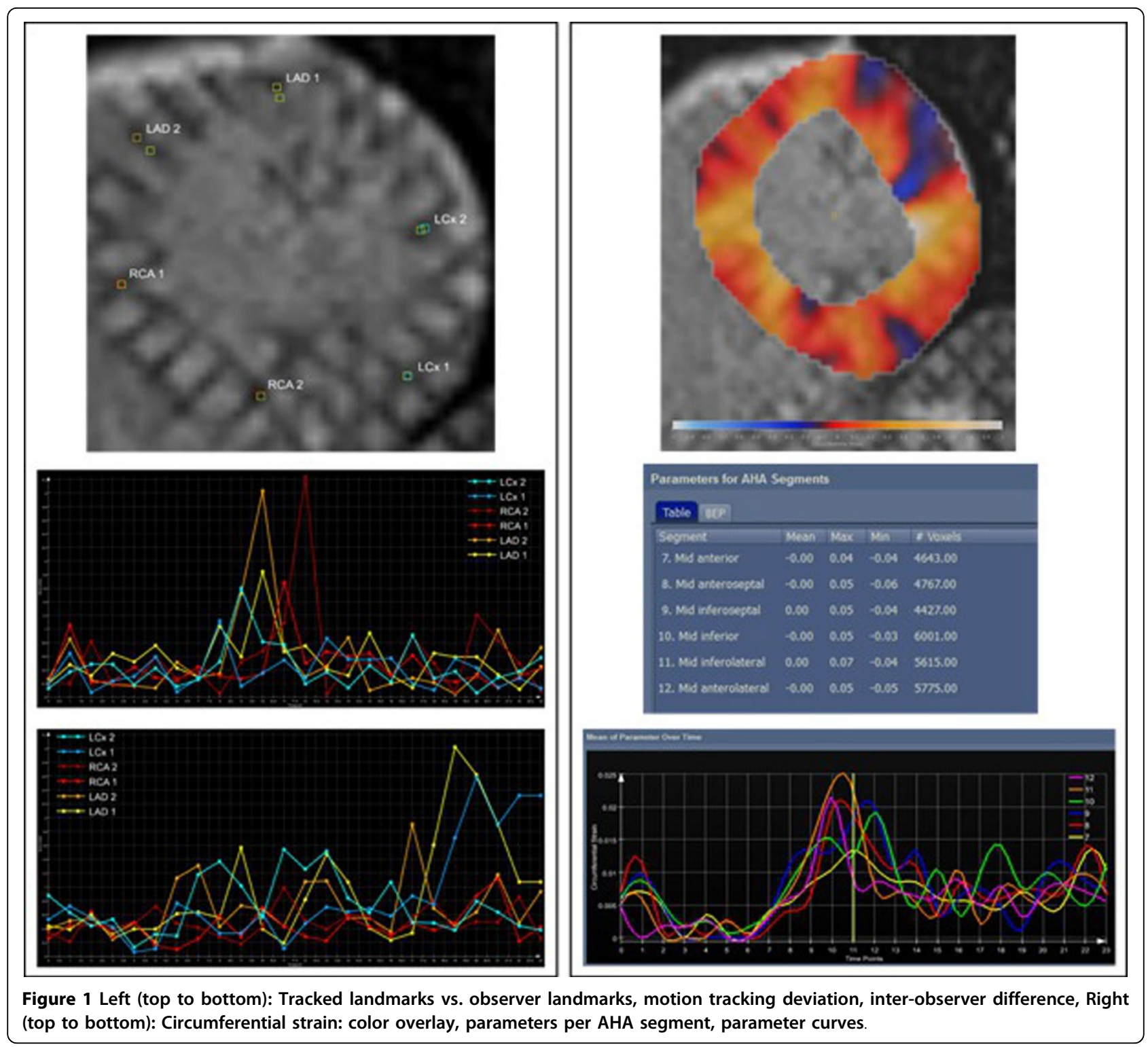

\section{Authors' details}

${ }^{1}$ Fraunhofer MEVIS, Bremen, Germany. ${ }^{2}$ University Hospital Tübingen,

Tübingen, Germany.

Published: 16 January 2014

\section{References}

1. Tautz, et al: Motion Analysis with Quadrature Filter Based Registration of Tagged MRI Sequences. STACOM 2011, 78-87.

2. Knutsson, et al: Morphons: Paint on priors and elastic canvas for segmentation and registration, Image Analysis. Lecture Notes in Computer Science 2005, 3540:292-301.

doi:10.1186/1532-429X-16-S1-P365

Cite this article as: Tautz et al:: Evaluation of a phase-based motion tracking method for the calculation of myocardial stress and strain from tagged MRI. Journal of Cardiovascular Magnetic Resonance 201416 (Suppl 1):P365

Submit your next manuscript to BioMed Central and take full advantage of:

- Convenient online submission

- Thorough peer review

- No space constraints or color figure charges

- Immediate publication on acceptance

- Inclusion in PubMed, CAS, Scopus and Google Scholar

- Research which is freely available for redistribution 